\title{
Degradación ruminal de materia seca de Morus sp en caprinos en diferentes estaciones del año
}

\author{
Zach, A.; Trulls, H.E.; Ortíz, M.L.; Brem, J.J.; Brem, J.C. \\ Laboratorio de Análisis Físico-Químicos anexo a la Cátedra de Biofísica, Facultad de Ciencias Veterinarias, \\ Universidad Nacional del Nordeste, Sargento Cabral 2139 (3400), Corrientes, Argentina. Tel 03794430101. \\ E-mail: jjbrem@hotmail.com
}

\begin{abstract}
Resumen
Zach, A.; Trulls, H.E.; Ortíz, M.L.; Brem, J.J.; Brem, J.C.: Degradación ruminal de materia seca de Morus sp en caprinos en diferentes estaciones del año. Rev. vet. 28: 2, 141-144, 2017. El objetivo del trabajo fue estudiar la degradabilidad ruminal de la materia seca (MS) de hojas de morera en caprinos. Se procedió a determinar el contenido de MS por secado de las muestras en estufa a $105^{\circ} \mathrm{C}$ durante $12 \mathrm{~h}$. Para la evaluación de la cinética de degradación de MS se utilizó la técnica de digestión ruminal in situ, en 4 caprinos machos con fístula ruminal permanente. En cada estación se incubaron muestras de $3 \mathrm{~g}$ del forraje en bolsitas de dacrón con una porosidad de $50 \mu \mathrm{m}$. Los tiempos de incubación fueron $0,6,12$, 24,48 y $72 \mathrm{~h}$; luego de retiradas las bolsitas fueron colocadas en estufa a $60^{\circ} \mathrm{C}$ durante $48 \mathrm{~h}$ y pesadas para cuantificar la MS degradada por diferencia de peso del material desaparecido. Los datos fueron analizados con los programas estadísticos SAS e Infostat. Los resultados obtenidos mostraron que la fracción soluble se mantuvo constante en otoño y primavera, disminuyendo hacia el verano $(\mathrm{p}<0,05)$ y que para la fracción indigerible se registraron aumentos en el verano. La fracción lentamente degradable, la tasa de degradación ruminal y el tiempo de inicio de la degradación, no presentaron variaciones horarias ni estacionales. La degradabilidad potencial de la MS presentó valores altos en las distintas estaciones, mientras que la degradabilidad efectiva -en donde se asumió una tasa de pasaje del 4\%- se mantuvo constante. Como conclusión se destaca el alto índice de degradabilidad de MS que presenta esta especie forrajera durante las tres estaciones del año evaluadas y que los compuestos de la pared celular del follaje de morera no impedirían que las bacterias y demás microorganismos celulolíticos de la flora ruminal efectúen una eficiente digestión.
\end{abstract}

Palabras clave: cabra, morera, materia seca, rumen, degradabilidad.

\begin{abstract}
Zach, A.; Trulls, H.E.; Ortíz, M.L.; Brem, J.J.; Brem, J.C.: Ruminal degradation of dry matter from Morus sp in goats at different seasons. Rev. vet. 28: 2, 141-144, 2017. The aim of this work was to evaluate the ruminal degradability of dry matter (DM) of mulberry leaves in goats. The DM content was determined by drying the samples at $105^{\circ} \mathrm{C}$ for $12 \mathrm{~h}$. In situ ruminal digestion technique was used to evaluate the degradation kinetics of DM of Morus sp in 4 castrated male goats with permanent ruminal fistula, by incubating $3 \mathrm{~g}$ forage samples in dacron bags with a porosity of $50 \mu \mathrm{m}$. Incubation times were $0,6,12,24,48$ and 72 hours. Then, bags were placed in oven at $60^{\circ} \mathrm{C}$ for $48 \mathrm{~h}$ and weighed to quantify the degraded DM by difference of the remaining material. Data were analyzed with $S A S$ and Infostat software. The results showed that the soluble fraction remained constant in autumn and spring, declining in summer $(p<0.05)$; the rate of degradation from the slowly degradable fraction increased in summer. The slowly degradable fraction and the start time of degradation showed no time or seasonal variations. The potential degradability of DM showed high values for the three seasons, while the effective degradability -where a passage rate of $4 \%$ was assumed- remained constant. In conclusion, the high rate of degradability of DM of this forage during the three seasons of the year is notable. The high degradability of the cell wall of mulberry's leaves is also remarkable, as it did not affect the digestion process by cellulolytic microorganisms of the rumen.
\end{abstract}

Key words: goat, mulberry, dry matter, rumen, degradability. 


\section{INTRODUCCIÓN}

Las hojas de árboles son utilizadas en muchas partes del mundo como una fuente potencial de proteínas y fibra para el ganado; en regiones tropicales se usan en la alimentación de rumiantes debido a su alto valor nutritivo y a sus efectos positivos sobre la función ruminal ${ }^{15,24,25}$.

La morera (Morus $s p$ ) es un árbol de uso múltiple, cuyas hojas pueden ser utilizadas en nutrición animal por su alto potencial forrajero. En ese sentido se vienen realizando numerosos estudios que demuestran la versatilidad de la planta tanto en zonas tropicales como subtropicales, destacándose su utilidad como banco de proteínas para potreros con pasturas de baja calidad nutricional, resultando ser comparable con arbustos leguminosos multipropósitos y especialmente recomendados para ser implementados por pequeños y medianos productores ${ }^{9}$.

Estas evaluaciones comenzaron en la década de los ochenta en América Central, indicándose su uso en sistemas de cría de ovinos, caprinos, bovinos y de algunos monogástricos (cerdos, aves y conejos). Un informe del Servicio de Producción Animal del Departamento de Agricultura de la FAO ${ }^{11}$, establece que en su composición la morera contiene más elementos nutritivos digeribles que la mayoría de los forrajes tradicionales.

Se destaca por su excelente capacidad de producción de biomasa ${ }^{4}$, composición química ${ }^{8}$, adaptabilidad a diversas condiciones de clima y suelo ${ }^{7}$ y disponibilidad $^{2,5}$. Su follaje presenta concentraciones proteicas entre 15 y $28 \%$ y su composición de aminoácidos es similar a la de la harina de soya, siendo considerada como una buena fuente de aminoácidos, de los cuales casi la mitad son los considerados esenciales ${ }^{19}$.

La proteína bruta de la morera tiene una digestibilidad in vivo del $90 \%{ }^{13}$; las concentraciones de nitrógeno, potasio y calcio son altas, alcanzando valores de 3,$35 ; 2,0$ y $2,5 \%$ respectivamente ${ }^{10}$; las acumulaciones cuantitativas de calcio se presentan en los idioblastos de las células ${ }^{23}$. Los contenidos de cenizas totales pueden llegar a ser superiores al $15 \%$ dependiendo del grado de fertilización del suelo, aunque normalmente oscilan entre 10 y $15 \%{ }^{21}$. Esta planta presenta apreciables niveles de vitaminas, fundamentalmente $\mathrm{C}$ y grupos B; destacándose las concentraciones de riboflavina y los ácidos nicotínico, pantoténico ${ }^{12}$ y ascórbico $(0,3 \%$ MS) 22 .

Una de las cualidades principales de la morera como forraje es su alta palatabilidad, tanto que los animales la prefieren inicialmente sobre otros forrajes simultáneamente ofrecidos. Los pequeños rumiantes consumen ávidamente sus hojas y tallos tiernos, aún cuando no la hayan conocido previamente; si es suministrado entero fácilmente pueden separar las hojas del tallo; los bovinos consumen la totalidad de la biomasa si la planta esta finamente molida ${ }^{20}$.

Utilizada como suplemento en la alimentación de rumiantes arrojó buenos resultados. En cabras lecheras se registraron incrementos de producción de 2,0 a 2,5 $\mathrm{kg} / \mathrm{animal} /$ día cuando la suplementación con morera pasó del 1,0 al 2,6\% del peso vivo (PV), con ligeros incrementos en los contenidos de grasa, proteína y sólidos totales de la leche ${ }^{18}$. En corderos alimentados con una dieta base de king-grass, se reportaron ganancias de peso de 60, 75, 85 y $101 \mathrm{~g} /$ animal/día cuando se suplementaron con morera a razón del $0 ; 0,5 ; 1,0$ y 1,5\% del PV ${ }^{1}$

El objetivo del presente trabajo fue evaluar en caprinos la cinética de degradación ruminal de la materia seca de hojas de morera, en tres estaciones del año.

\section{MATERIAL Y MÉTODOS}

Para determinar la degradabilidad de la MS se utilizó la técnica de digestión ruminal in situ ${ }^{17}$, en cuatro caprinos machos castrados, de 18 meses de edad, que fueron individualmente estabulados y recibieron una dieta base de heno de alfalfa a discreción y $250 \mathrm{~g}$ de maíz molido; estos animales fueron fistulizados en forma permanente por cirugía de rumen y colocación de fístula de PVC. A través de ellas se incubaron en el ambiente ruminal bolsitas de dacrón con una porosidad de $50 \mu \mathrm{m}$.

Se procedió a la recolección de hojas de morera en tres estaciones del año, luego de 30 días de efectuada una poda manual. El contenido de MS se determinó por secado en estufa a $105^{\circ} \mathrm{C}$ por 12 horas y luego acondicionadas para su conservación hasta realizar las pruebas.

En cada estación del año -excepto invierno- se realizaron 4 repeticiones de muestras desecadas y molidas de $3 \mathrm{~g}$ de forraje en cada bolsa, que fueron colocadas dentro del rumen. Las bolsas fueron remojadas previamente en agua durante $15 \mathrm{~min}$ antes de ser introducidas secuencialmente a las $0,6,12,24,48$ y $72 \mathrm{~h}$ y luego retiradas en forma simultánea.

Una vez finalizado cada uno de los períodos estacionales, las bolsas fueron lavadas con agua fría durante 5 min, colocadas en estufa a $60^{\circ} \mathrm{C}$ durante $48 \mathrm{~h}$ y luego pesadas individualmente para cuantificar por diferencia el material remanente.

Los datos de la degradación ruminal de MS se calcularon por diferencia entre el peso inicial y final de cada muestra; la pérdida de peso fue considerada como el valor de desaparición de MS. La cinética de la degradación fue determinada por un modelo convencional ${ }^{16}$ :

MS $\%=a+b\left(1-e^{-c t}\right)$, donde: MS $\%=$ degradabilidad de MS al tiempo "t" dado en \%. (a) = fracción soluble. $(b)=$ fracción lentamente degradable. $(c)=$ tasa de degradación de $\mathrm{b}$ en horas. $(\mathrm{t})=$ tiempo de incubación ruminal en horas. (e) = base del logaritmo neperiano.

La degradabilidad efectiva $(\mathrm{P})$ se calculó mediante la ecuación ${ }^{14}: \mathrm{P}=\mathrm{a}+\mathrm{bc} / \mathrm{c}+\mathrm{k}$, donde: $\mathrm{P}=$ es degradabilidad efectiva, $\mathrm{a}=$ fracción eliminada rápidamente por el lavado, $\mathrm{b}=$ fracción lentamente degradable, $\mathrm{c}=$ constante del ritmo de degradación de b, y $\mathrm{k}=$ ritmo fraccional del pasaje desde el rumen (asumido como 
una constante a una velocidad de 0,04 por hora, su valor fue seleccionado de acuerdo con la retención promedio en este tipo de dieta).

Para estimar las fracciones a, b, kd (tasa de degradación) y lag (tiempo de inicio de la degradación), se utilizó un programa no lineal PROC NLIN del Softward estadístico SAS V9. 2008, disponible en el INTA EEA de "Colonia Benítez" (Provincia del Chaco). La fracción “c”, se calculó por diferencia entre 100 y la suma de $a+b$. Con el programa estadístico Infostat (Versión 2003) se determinaron las variaciones de la degradabilidad en las distintas estaciones del año mediante análisis de la varianza; para la comparación de medias se usó la prueba de Tuckey y se aceptó una significación estadística de un $\mathrm{p}<0,05$.

\section{RESULTADOS Y DISCUSIÓN}

En el Tabla 1 se presentan los valores de las constantes de degradabilidad ruminal de la materia seca de morera, contenidas en las partes estructurales. En el análisis estadístico se puede observar que la fracción soluble (valor de a) se mantuvo constante en otoño y primavera disminuyendo hacia el verano $(\mathrm{p}<0,05)$. La fracción indigerible (c) también registró diferencias significativas aumentando en el verano $(\mathrm{p}<0,05)$.

La fracción lentamente degradable (b) no registró variaciones significativas al igual que la tasa de degradación ruminal $(\mathrm{kd})$ y el tiempo de inicio de la degradación (lag). La degradabilidad efectiva (P), en donde se asumió una tasa de pasaje del $4 \%$, se mantuvo constante durante las tres estaciones analizadas, obteniéndose valores similares a los reportados por otros autores ${ }^{6}$.

La degradabilidad potencial de la MS $(a+b)$ de la hoja de Moruss sp osciló entre 93,25\% en otoño y $83,86 \%$ en verano, guarismos que fueron superiores a las de otro ensayo realizado ${ }^{6}$ donde además de la hoja se valoró la degradabilidad de tallos y planta entera en diferentes edades de rebrote. Estos valores obtenidos son determinados fundamentalmente por una mayor fracción lentamente degradable (b), que se mantiene en las tres estaciones evaluadas, la disminución de la fracción soluble (a) en verano no afecta la degradación potencial, debido al buen valor de (b) en dicha estación.

En la Figura 1 se observa el alto índice de degradabilidad de MS (aproximadamente $90 \%$ ), lo que demuestra la elevada calidad nutricional de esta especie forrajera. Esto es coincidente con la digestibilidad reportada por otros autores sobre esta planta cuando fue utilizada como suplemento ${ }^{3,18}$ y es mayor a los valores informados en estudios comparativos de digestibilidad y composición química entre mora y tres especies de leguminosas ${ }^{24}$.

Por otra parte, es importante destacar que la digestibilidad de este forraje puede variar con la dieta base aportada. Esto quedó demostrado en un estudio
Tabla 1. Parámetros de degradabilidad ruminal in situ de MS de Morus sp en las tres estaciones del año.

\begin{tabular}{lccccc}
\hline parámetro & otoño & primavera & verano & EE & $\mathrm{p}$ \\
\hline $\mathrm{a}(\%)$ & $23,66 \mathrm{~b}$ & $23 \mathrm{~b}$ & $11,33 \mathrm{a}$ & 0,11 & 0,0015 \\
$\mathrm{~b}(\%)$ & 69,59 & 68,36 & 72,53 & 0,92 & 0,21 \\
$\mathrm{c}(\%)$ & $6,75 \mathrm{a}$ & $8,64 \mathrm{a}$ & $16,15 \mathrm{~b}$ & 0,95 & 0,0048 \\
$\mathrm{kd}(\%)$ & 0,04 & 0,07 & 0,06 & 0,01 & 0,18 \\
lag (h) & 7,68 & 6,25 & 7,33 & 1,28 & 0,69 \\
$\mathrm{P}(\%)$ & 67,35 & 69,72 & 69,46 & 0,91 & 0,25 \\
\hline
\end{tabular}

a: fracción soluble; b: fracción de degradación lenta; c: tasa de degradación de "b" en horas; EE: error estándar; p: probabilidad; P: degradabilidad efectiva. En cada fila, letras distintas indican diferencias significativas entre medias (test de Tukey, $p<0,05$ ).

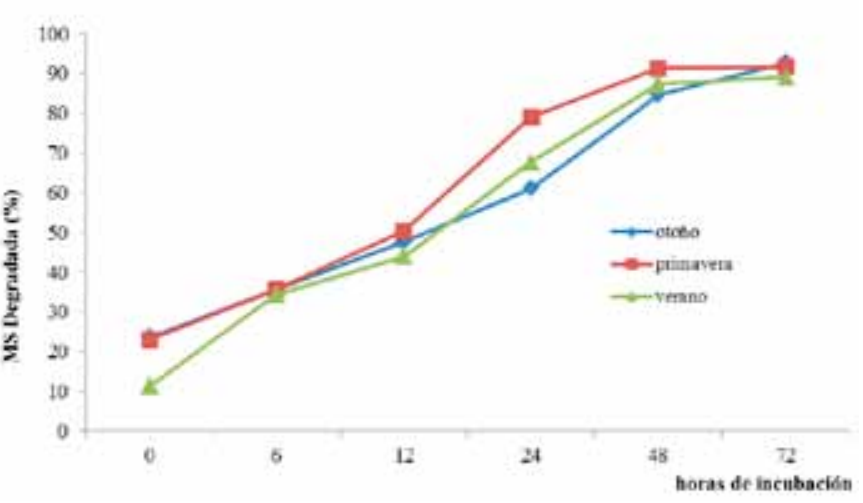

Figura 1. Cinética de degradación ruminal de la MS de Morus $s p$ en los distintos tiempos de incubación, durante as tres estaciones.

de degradación de MS y PC de morera in situ en ovinos con tres tratamientos de dietas base diferentes, que generaron distintos ambientes ruminales, concluyendo que la composición de la dieta afecta los parámetros de degradabilidad de MS de este recurso ${ }^{26}$.

Como conclusión, se destaca el alto índice de degradabilidad de la materia seca que presentó este recurso forrajero durante las tres estaciones del año evaluadas, a pesar de tratarse de una especie leñosa.

Agradecimientos. A los doctores Balbuena, O. y Kucseva, C.D., del INTA Colonia Benitez, (Chaco), por el asesoramiento en el manejo e interpretación de los datos del programa estadístico SAS.

\section{REFERENCIAS}

1. Benavides JE. 1986. Efecto de diferentes niveles de suplementación con follaje de morera (Morus sp) sobre el crecimiento y consumo de corderos alimentados con pasto. Serie Técnica CATIE (Turrialba, Costa Rica), 67: 40-42.

2. Benavides JE. 1994. La investigación en árboles forrajeros. En: Árboles y arbustos forrajeros en América Central (Benavides JE, Ed.), Serie Técnica CATIE (Turrialba, Costa Rica), 236: 3-21.

3. Benavides JE. 1995. Manejo y utilización de la morera (Morus alba) como forraje. Agroforest Am 7: 27-30. 
4. Benavides JE. 2000. La morera, un forraje de alto valor nutricional para la alimentación animal en el trópico. Past \& Forraj 23: 1-11.

5. Benavides JE. 2002. Utilization of mulberry in animal production systems. Anim Prod Health Paper 147: 291-327.

6. Boschini C. 2001. Degradabilidad in situ de la materia seca, proteína y fibra del forraje de morera (Morus alba). Agron Mesoam 12: 79-87.

7. Datta RK. 2002. Mulberry cultivation and utilization in India. Anim Prod Health Paper 147: 45-62.

8. Duke JA. 1983. Morus alba (L.). http://newcrop.hort.purdue.edu/newcrop/duke-energy.

9. Ebrahim A, Animut G, Urge M, Hailemichael A. 2015. Mulberry (Morus alba) as energy potential opportunity for livestock feed development in northern Ethiopia. $J \mathrm{Ag}$ ric Sci Food Technol 1: 66-72.

10. Espinoza E, Benavides J. 1996. Efecto del sitio y de la fertilización nitrogenada sobre la producción y calidad del forraje de tres variedades de morera (Morus alba L.). Agroforest Am 3: 24-27.

11. FAO. 1990. Sericulture training manual. FAO. Bulletin Agricultural Services (FAO Rome) 80: p.117.

12. Ho-Zoo L, Won-Chu L. 2001. Utilization of mulberry leaf as animal feed: feasibility in Korea. In: Mulberry for animal feeding in China (Jian L, Yuyin C, Sánchez M, Xingmeng L, Ed.), Hangzhou, China, p. 75.

13. Jegou D, Waelput JJ, Brunschwig G. 1994. Consumo y digestibilidad de la materia seca y del nitrógeno del follaje de morera (Morus sp) y amapola (Malvabiscus arboreus) en cabras lactantes. In: Árboles y arbustos forrajeros en América Central (Benavides JE, Ed.)". Serie Técnica CATIE (Turrialba, Costa Rica), 236: 155-162.

14. McDonald I. 1981. A revised model for the estimation of protein degradability in the rumen. J Agric Sci 96: 251252.

15. Omar SS, Shayo CM, Udén P. 1999. Voluntary intake and digestibility of mulberry (Morus alba) diets by growing goats. Trop Grassl 33: 177-181.
16. Orskov ER, McDonald IM. 1979. Estimation of protein degradability in the rumen from incubation measurement weighted according to rate of passage. J Agric Sci 96: 499503.

17. Orskov ER, Hovell FD, Moul F. 1980. Uso de la técnica de la bolsa de nylon para evaluación de los alimentos. Prod Anim Trop 5: 195-213.

18. Rojas H, Benavides JE, Fuentes M. 1994. Producción de leche de cabras alimentadas con pasto y suplementadas con altos niveles de morera. Serie Técnica CATIE (Turrialba, Costa Rica), 236: 305-320.

19. Sánchez MD. 2002. World distribution and utilization of mulberry and its potential for animal feeding. Anim Prod Health 147: 1-8.

20. Sanchez MD. 2002. Mulberry, an exceptional forage available almost worldwide. In: Mulberry for animal production (Sanchez MD Ed), Publ. FAO, Rome, p. 271-289.

21. Shayo CM. 1997. Uses, yield and nutritive value of mulberry (Morus alba) trees for ruminants in the semi-arid area of central Tanzania. Trop Grassl 31: 599-604.

22. Singh B, Makkar HP. 2002. The potential of mulberry foliage as a feed supplement in India. Anim Health Prod 147: 139-155.

23. Sugimura Y et al. 1999. Calcium deposition in idioblasts of mulberry leaves. Ann Botany 83: 543-550.

24. Vu CC, Verstegen MW, Hendriks WH, Pham, KC. 2011. The nutritive value of mulberry leaves (Morus alba) and partial replacement of cotton seed in rations on the performance of growing vietnamese cattle. J Anim Sci 24: 12331242.

25. Yao J, Yan B, Wang XQ, Lui JX. 2000. Nutritional evaluation of mulberry leaves as feeds for ruminants. Livest Res Rural Dev 12: 2. On line: http://www.lrrd.org/lrrd

26. Yulistiani D, Jelan ZA, Liang JB. 2008. Degradability of mulberry (M. alba) and rice bran in the rumen of sheep fed different diets. Indonesian J Anim Vet Sci 13: 264-272. 